West Virginia Agricultural and Forestry Experiment Davis College of Agriculture, Natural Resources Station Bulletins

$1-1-1961$

\title{
Rainfall probability and its applications
}

Jerry C. Burchinal

W.H. Dickerson

Follow this and additional works at: https://researchrepository.wvu.edu/ wv_agricultural_and_forestry_experiment_station_bulletins

\section{Digital Commons Citation}

Burchinal, Jerry C. and Dickerson, W. H., "Rainfall probability and its applications" (1961). West Virginia Agricultural and Forestry Experiment Station Bulletins. 454.

https://researchrepository.wvu.edu/wv_agricultural_and_forestry_experiment_station_bulletins/429 @ WVU. It has been accepted for inclusion in West Virginia Agricultural and Forestry Experiment Station Bulletins by an authorized administrator of The Research Repository @WVU. For more information, please contact ian.harmon@mail.wvu.edu. 
West Virginia University Libraries 



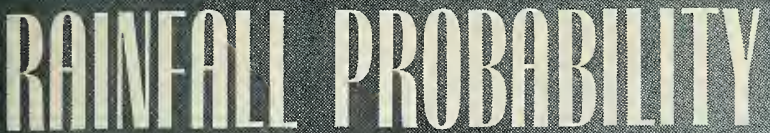

... and its applications

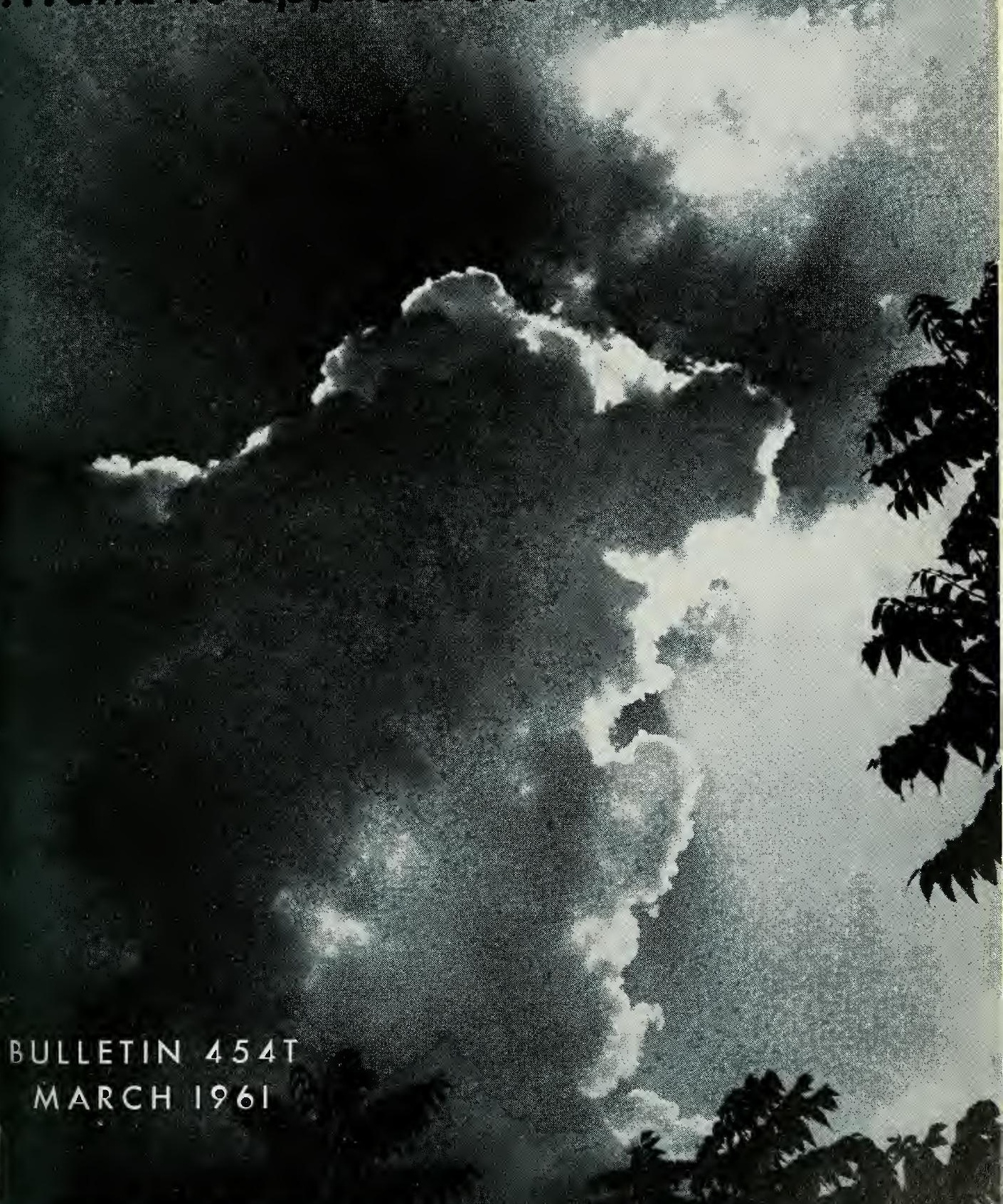


Digitized by the Internet Archive in 2010 with funding from

Lyrasis Members and Sloan Foundation 


\section{CONTENTS}

INTRODUCTION

Probability Methods

Applications for Frequent Estimates

Case I. Average Annual Precipitation for the State 7

Case II. Annual Rainfall by Water Years

Case III. Weekly Rainfall

Case IV. Monthly Rainfall

SUMMARY

APPENDIX A

Determination of a Frequency Line by the Kimball Equation

ApPENDIX B

Frequency of Rainfall by the Log-Probability Method.

ApPENDIX C

The Incomplete Gamma Distribution 


\title{
THE AUTHORS
}

J. C. Burchinal is Associate Professor of Civil Engineering in the College of Engineering and W. H. Dickerson is Professor of Agricultural Engineering in the College of Agriculture, Forestry, and Home Economics, and Agricultural Engineer in the Agricultural Experiment Station.

This study was supported in part by the Northeast Regional Project NE-35, "Application of Climatology to Northeastern Agriculture," a cooperative effort involving the agricultural experiment stations of the Region and the Weather Bureau of the United States Department of Commerce.

(Cover photograph by David R. Creel)

\author{
West Virginia UNIVERSITY \\ Agricultural Experiment Station \\ College of Agriculture, Forestry, and Home Economics \\ A. H. Vanlandingham, Director \\ MORGANTOWN
}




\section{Rainfall Probability And Its Applications}

\section{J. C. BURCHINAL and W. H. DICKERSON}

\section{Introduction}

RECIPITATION, or rainfall, as it is often called in popular usage, has been measured and recorded for a number of West Virginia stations for about 60 years. Continuous records of good quality are available for 24 stations back to 1926. Data from these stations on precipitation and temperature have been entered on punched cards for ease of tabulation and analysis under a cooperative arrangement with the U. S. Weather Bureau, and the Northeast Regional Project, NE-35, "Application of Climatology to Northeastern Agriculture."

These records have many uses in engineering and agriculture. One useful purpose is in the preparation of rainfall probability estimates. These estimates, which can be conveniently represented as frequency curves, can be used to show the probable intensity or amount of rainfall. Frequency may be expressed as a percentage, or in terms of the return period in years. It should be understood that the expression of frequency as a return period in years implies no periodicity. Annual, seasonal, monthly, weekly, or shorter periods can be treated by various probability methods.

Estimates of rainfall probability are essential for solving many problems dealing with irrigation, drainage, stream flow, and the design of hydraulic structures. For example, the normalcy of rainfall during the period of an experiment in which rainfall influences the outcome should always be examined. Experimental work in irrigation, the measurement of runoff or erosion, or the determination of crop yields are always affected by the amount, distribution, or intensity of precipitation. The use of probability estimates offers a convenient method of comparing the period of record to the long-time expectancy. Thus it can be determined if the period in question is above, below, or near normal expectancy, or if the period contains years that represent a wide range in precipitation frequency.

Several methods have been advanced to determine rainfall probability. Some are relatively simple and easy to apply, whereas others involve mathematical formulas that are time consuming to solve. An ideal method 
of estimating probability would: (1) apply to any period of time such as a year, season, month, or week; (2) provide reliable estimates for a return period of 50 to 100 years by extrapolation; and (3) be easily and quickly computed. None of the probability methods now in common use meets all of these requirements. A consideration of the merits of the various probability methods is beyond the scope of this bulletin, the purpose of which is to illustrate some possible applications of rainfall frequency data which can be derived from the available climatological records.

\section{Probability Methods}

Three methods are illustrated for determining the probability, or frequency, of rainfall occurrences. These are: (1) the equation proposed by Kimball [5]; (2) the log-probability method; and (3) the incomplete gamma distribution. It is believed that each method is generally applicable to the type of problem for which it is used. In some cases, similar results can be secured and the same conclusion reached by any of the three methods.

The Kimball formula (5) and other similar plotting equations determine a plotting position for hydrologic events such as rainfall amounts in terms of recurrence intervals or per cent frequency. These points can be plotted (probability paper is often used for convenience) and the line of best fit drawn by eye. If the data are normally distributed, the points will approach a straight line on arithmetic probability paper. If the logarithms of the data are normally distributed, the frequency will appear as a straight line on logarithmic probability paper. Such methods are the simplest to use. However, a high degree of subjectivity is sometimes involved in drawing the curve of best fit.

The log-probability method was devised by Hazen (4) and later improved by Chow (2). It is used later to study annual runoff and rainfall. Annual hydrologic events, such as flood peak or volume and annual rainfall amounts, often approach a normal distribution. The data is said to be skewed if it does not fit the normal curve. The log-probability method offers one means of handling such data. By use of the method, a transformation is obtained that will result in a straight line on logarithmic probability̆ paper.

The incomplete gamma function has been suggested by Barger and Thom (1) as a model for representing rainfall distribution. Weekly rainfall totals do not usually exhibit normal distribution characteristics because of the large number of weeks with zero rainfall. It has been proposed that the incomplete gamma distribution may offer an appropriate 
model for smoothing rainfall probability curves for weekly, monthly, or seasonal amounts. Friedman and Janes (3), in applying the method to Connecticut precipitation data, concluded that most irregularities in the shape of cumulative probability curves based on a 30-year sample are not significant, and that the incomplete gamma affords a sound basis for smoothing out such irregularities.

\section{Applications for Frequency Estimates}

In the following section, frequency curves are illustrated and there is a brief explanation of how they may be used for various purposes and by different interests. The curves in the examples are based on the Kimball equation, the log-probability method, and the incomplete gamma model. This order is arrayed somewhat on the ease of computation of a frequency line, beginning with the simple and proceeding to the more complex. Examples of the computations required for each case are given in the Appendixes.

\section{CASE 1. Average Annual Precipitation for the State}

The frequency line for the average rainfall over the State as determined by the Kimball equation is shown in Figure 1. The average annual rainfall over the State was determined by the station average method, i.e., the arithmetic average of all stations reporting, disregarding differences in areal coverage.

A plotting position was determined for each annual rainfall amount by means of the plotting equation. The points were plotted on logarithmic probability paper, and the line of best fit drawn by eye. Individual points that fell far out of line were given small weight in determining the position of the line.

Figure 1 shows that the points between 5 and 95 per cent frequency approach a straight line. This can be interpreted as indicating that more confidence can be given to the line between these limits than can be ascribed to the extremities. The point representing the 25.43 inches for 1930 is not in good agreement with the remainder of the data. This may be due to any of a number of reasons, for example, the data are not normally distributed, the data are not a representative sample, or the low figure of 25.43 inches may represent a drought with a recurrence interval much longer than the 33-year return period assigned by the plotting equation.

The frequency line of average annual rainfall over the State is of general interest for studying the droughtiness, normalcy, or excessive rainfall characteristics of selected years or periods. Appendix Table A contains the annual average rainfall for the State for the period 1926-1957, 


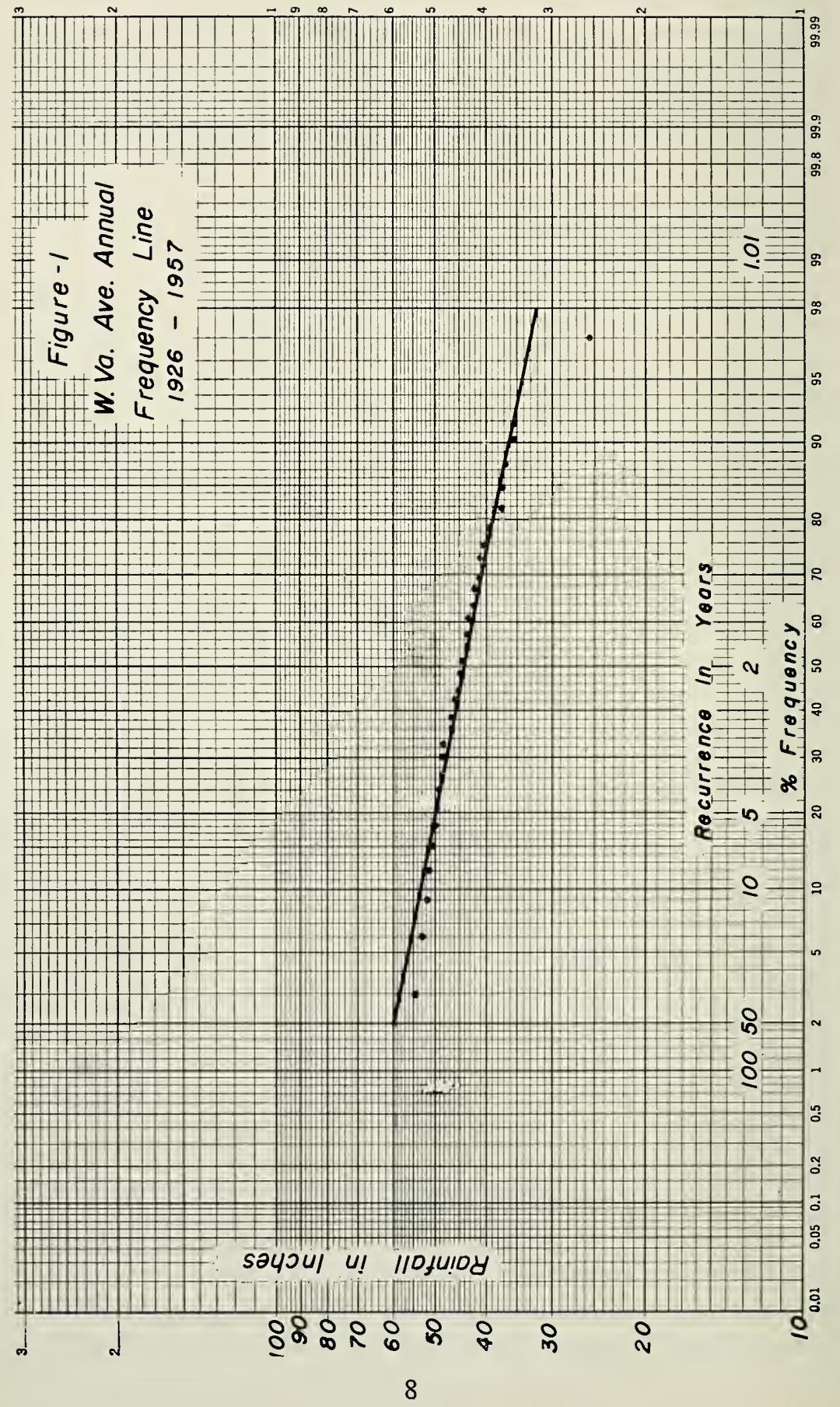


1nclusive. It has been mentioned that the dry year of 1930 is outstanding. In comparison, the droughty season of 1953, which may have been as severe as any experienced at some localities (this point has not been investigated) did not approach the State-wide deficiency that existed in 1930. At the other extreme, a high rainfall such as the 54 inches experienced in 1950 can be expected to have a return period of about 15 years, as determined from the frequency line.

Data such as the foregoing are needed in connection with work involving drainage, erosion control, irrigation, flood control, water supply and related problems.

\section{CASE II. Annual Rainfall by Water Years}

A hypothetical case which serves to illustrate the use of an annual rainfall frequency curve in engineering follows: Assume that an industry wishes to use the runoff supplied by the 63.59-sq. mi. Deckers Creek drainage area near Morgantown, West Virginia. Further assume that this industry has determined that it will need 14 inches of runoff annually in order to supply its water needs. A tabulaton of actual data is shown in Table 1.

TABLE 1. Annual Runoff, Deckers Creek Drainage Area, and Rainfall, Morgantown Lock and Dam, Morgantown, West Virginia*

\begin{tabular}{c|c|c}
\hline \hline $\begin{array}{c}\text { Water } \\
\text { Year }\end{array}$ & $\begin{array}{c}\text { Inches Runoff from Deckers } \\
\text { Creek Drainage Area }\end{array}$ & $\begin{array}{c}\text { Precipitation in } \\
\text { Inches Morgantown } \\
\text { Lock and Dam }\end{array}$ \\
\hline 1947 & 14.00 & 35.16 \\
1948 & 25.65 & 47.18 \\
1949 & 21.76 & 39.12 \\
1950 & 27.31 & 47.43 \\
1951 & 28.64 & 46.34 \\
1952 & 27.12 & 48.69 \\
1953 & 18.48 & 35.08 \\
1954 & 15.98 & 35.85 \\
1955 & 24.58 & 42.12 \\
1956 & 33.44 & 54.68 \\
\hline
\end{tabular}

* Runoff from United States Geological Survey data and rainfall from United States Weather Bureau records.

The record of runoff for the Deckers Creek drainage area is only as long as is shown in Table 1 , and statistical tests may be applied to show that these are insufficient data from which to plot a runoff frequency curve. However, the rainfall records go back a sufficient number of years so that a frequency curve may be constructed. Computations, 
based on a 26-water-year period, October 1 to September 30, inclusive, utilizing the log-probability method provided the frequency line shown in Figure 2 and the data shown in Table 2.

TABLE 2. Probability of Annual Rainfall, Morgantown Lock and Dam, Morgantown, West Virginia

\begin{tabular}{c|c|c}
\hline \hline $\begin{array}{c}\text { Frequency } \\
\text { (Per Cent) }\end{array}$ & $\begin{array}{c}\text { Recurrence Interval } \\
\text { (Years) }\end{array}$ & Inches \\
\hline 99 & 1.01 & 30.61 \\
50 & 2 & 42.08 \\
20 & 5 & 47.19 \\
5 & 20 & 52.71 \\
1 & 100 & 57.81 \\
\hline
\end{tabular}

Table 1 shows that 1947 gave the lowest percentage of runoff for the annual rainfall, namely 40 per cent. The amount of precipitation in that year was 35.16 inches. The probability that this amount would be equalled or exceeded in any year is, according to Figure 2, approximately 90 per cent. Stated in another way, the chances are that in one of ten years a rainfall of 35 inches or less will be experienced.

Since 14 inches was the minimum amount the industry had decided it would need, it could then decide whether it could afford to function with the probability of having insufficient water one year in ten on the average, or it could make some provision to take care of this deficiency.

If it can be assumed that the relationship of 40 per cent of the rainfall will be runoff for the dry years, the frequency curve might provide an estimate of how much additional water will be required by the industry in such years. The 95 per cent probability shows about 33.50 inches of rainfall. Forty per cent of this equals 13.4 inches. The deficiency would be 0.6 inch or about $660,000,000$ gallons which would have to be provided on a once in 20-year basis.

\section{CASE III. Weekly Rainfall}

Weekly frequency curves based on the incomplete gamma model are shown in Figure 3 for Elkins, West Virginia. Week numbers refer to the weeks of the climatological year beginning March 1. Thus, week 19 is the period of July 5-11, inclusive, and week 32 is October 4-10. At Elkins, week 19 and week 32 have, respectively, the greatest and least average precipitation for any period of the climatological year. For the driest week, the chances are about 15 per cent or one year in seven that rainfall of one inch or more will occur. For week 19, the wettest, the probability for this is 58 per cent. 


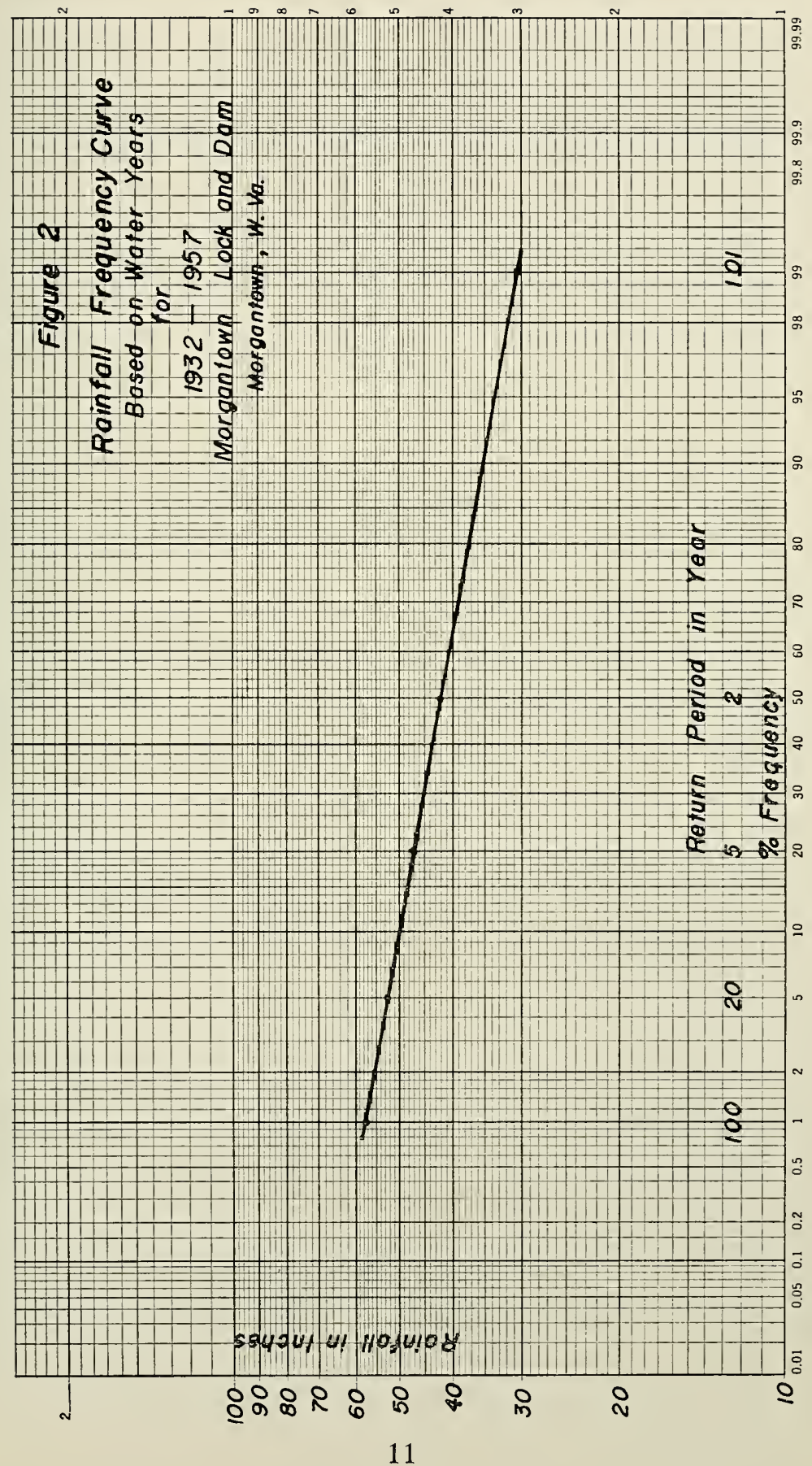




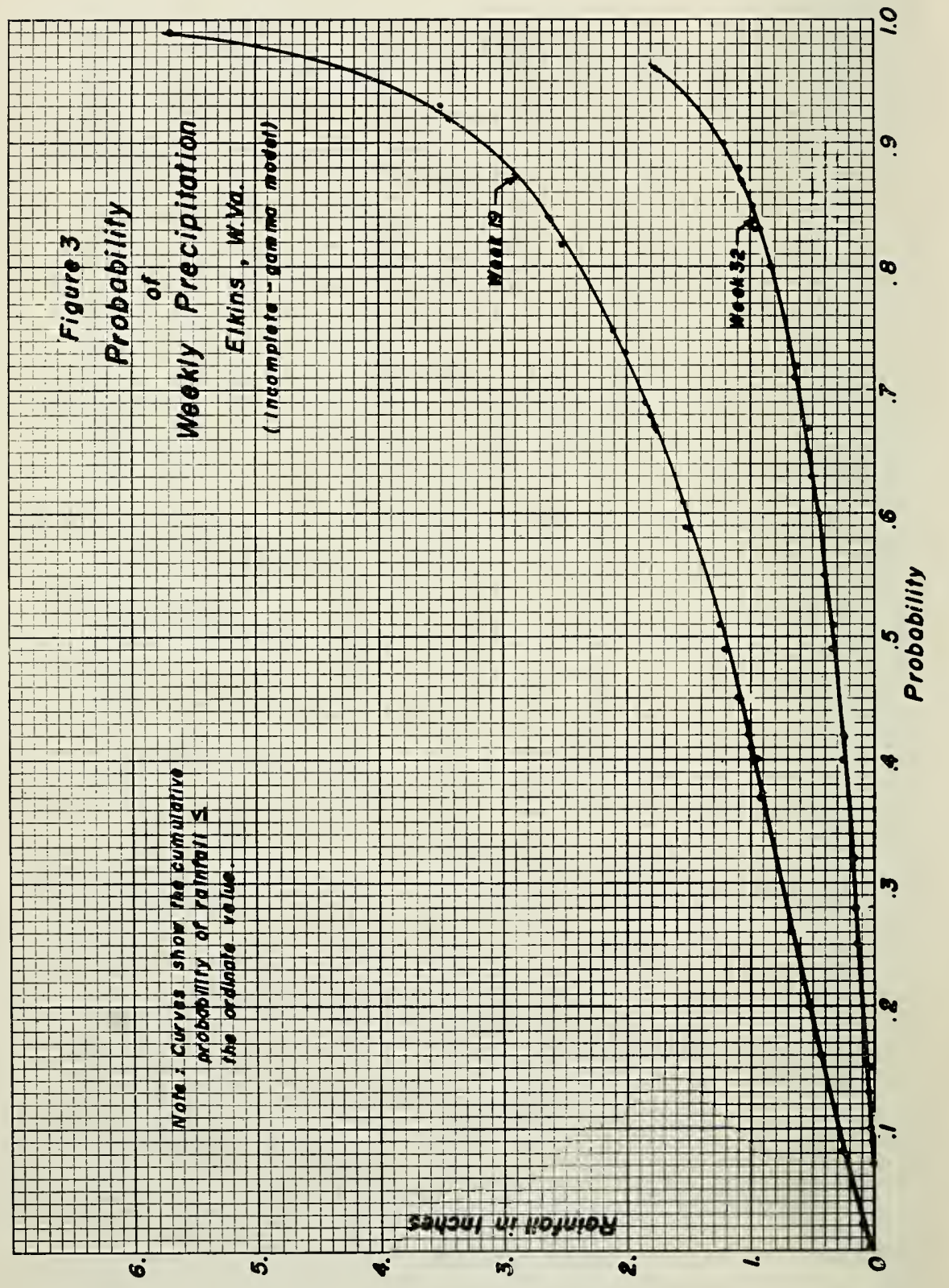


For an example of how such data might be put to practical use, the probability of weekly rainfall amounts might be considered as one of the factors in scheduling farming or other operations that are influenced by the weather. This presupposes that some latitude of choice exists. In the case cited, week 19 is likely to be a good period for growing forage crops in the general vicinity of Elkins, but unfavorable for harvesting such crops because of the relatively high rainfall. With sufficient information, the farm operator should be in a position to know whether to: (1) produce forage crops that can be harvested in a favorable climatic period, (2) ensile crops that can generally be expected to mature when weather conditions are unfavorable for making hay, or (3) provide drying equipment and select machinery and methods that minimize the weather hazard in harvesting forages.

\section{CASE IV. Monthly Rainfall}

One use of a monthly rainfall probability curve may be illustrated by the determination of the normalcy of May rainfall on the Reymann Memorial Farms, Wardensville, West Virginia, during the period in which irrigation experimental work was in progress there. May rainfall is probably a good indication of the need for, or the response to be expected by, the irrigation of the first cutting of forage crops. If the average rainfall for the months of May (3.31 inches at Wardensville) is assumed to be adequate, then the rainfall for the months of May during the period of the experiment can be compared to the computed frequency line to determine if they were near normal, or the relative wetness or dryness.

The May frequency curve for Wardensville (Figure 4) was determined by the incomplete gamma method. It has been determined that monthly rainfall is often skewed and not normally distributed. In Figure 4 the 50 per cent probability rainfall does not coincide with the average or mean of 3.31 inches. The frequency curves indicate that only about 42 per cent of the Mays will have precipitation equal to or greater than the average, or conversely that 58 per cent of the months of May can be expected to be equal to or less than this figure. Skewness of monthly rainfall is not confined to the station and period considered here, as 60 per cent of the months have less than normal precipitation and 40 per cent have more, according to Linsley, et al. (6). This feature of the distribution may sometimes lead to an over-optimistic view of the adequacy of the average monthly rainfall for crop production.

During the period of the irrigation experiment (1953-58), May of 1953 had the highest rainfall, although it is a matter of record that the following months in 1953 were very dry. Table 3 shows the relationship of the actual precipitation to the computed frequency line. 


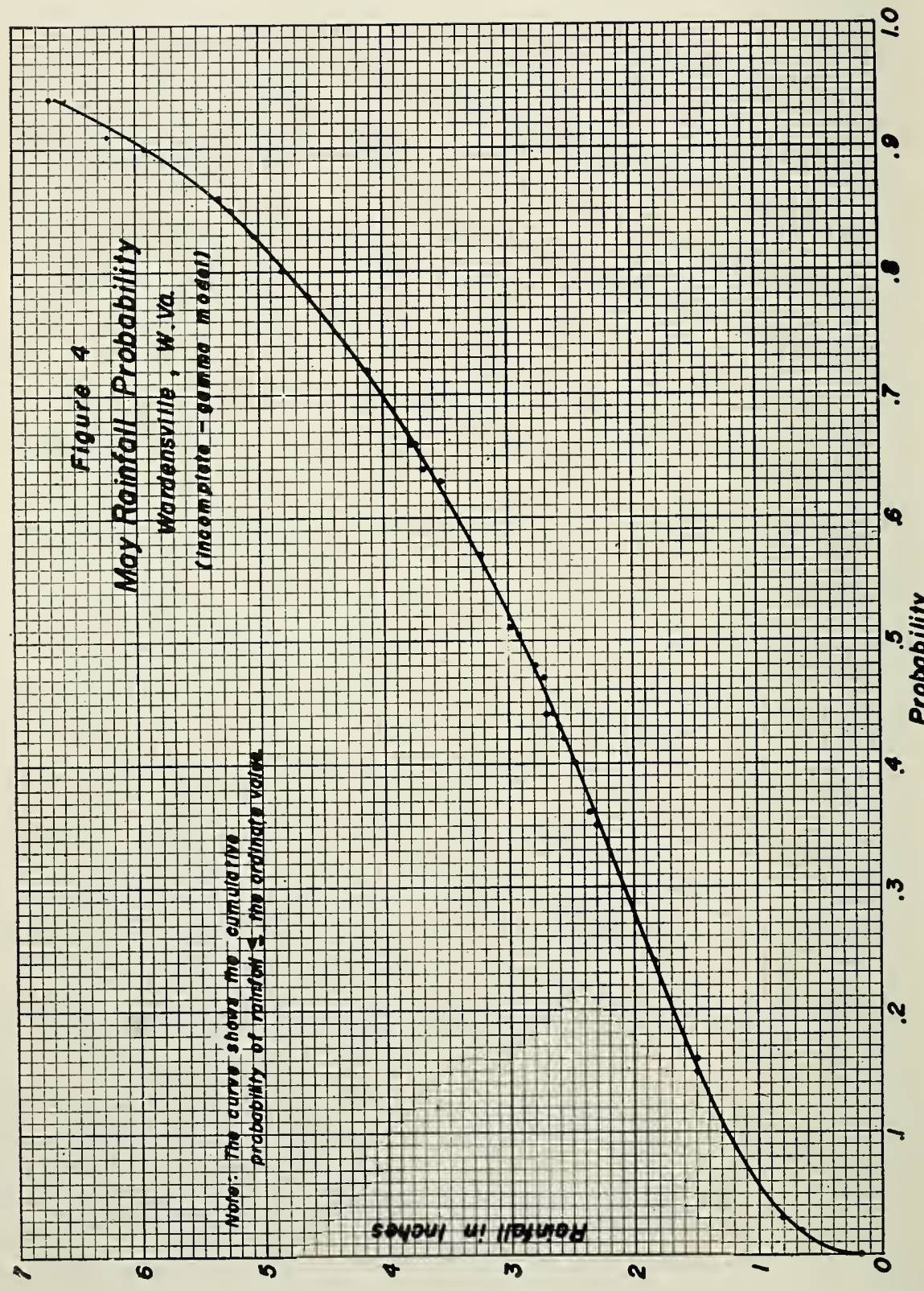


TABLE 3. Comparison of Recorded May Rainfall for the Period 1953-58 to the Expected Frequency of May Rainfall at Wardensville, West Virginia

\begin{tabular}{cc|c|c}
\hline \multicolumn{2}{c|}{$\begin{array}{c}\text { Recorded Rainfall } \\
\text { May }\end{array}$} & $\begin{array}{c}\text { Ordered Rainfall } \\
\text { May }\end{array}$ & $\begin{array}{c}\text { Probability from } \\
\text { Fig. 4 of rain- } \\
\text { fall } \leq \text { ordered }\end{array}$ \\
\hline 1953 & 5.94 ins. & 2.29 & $35 \%$ \\
1954 & 2.34 & 2.34 & $37 \%$ \\
1955 & 4.81 & 2.44 & $40 \%$ \\
1956 & 2.44 & 2.68 & $46 \%$ \\
1957 & 2.29 & 4.81 & $80 \%$ \\
1958 & 2.68 & 5.94 & $90 \%$ \\
\hline
\end{tabular}

Av. $(1926-1956)=3.31$ inches.

50 Per Cent Probability $=2.90$ inches.

These comparisons would seem to indicate that the 1953-58 period contained a good sample of wet and dry years, but that the period may not be indicative of results to be expected by the irrigation of forage crops when rainfall approximates either the long-time average or the 50 per cent chance which represents the median value.

\section{Summary}

Weather data, including temperature and precipitation records, have been entered on IBM punch cards for 24 West Virginia Stations beginning with January 1, 1926. This work was done in cooperation with the United States Weather Bureau and the Northeast Regional Project NE-35, "Application of Climatology to Northeastern Agriculture."

One of the possibilities for utilizing the precipitation data is for the preparation of rainfall probability or frequency estimates. Such estimates have been illustrated by computations for weekly, monthly, and seasonal rainfall amounts. Three methods of determining frequency curves have been used - the equation proposed by Kimball, the logprobability method, and the incomplete gamma distribution. Some possible applications illustrating the use of frequency curves in engineering and agriculture are suggested.

\section{References}

1. Barger, G. L. and Thom, H.C.S., "Evaluation of Drought Hazard." Agronomy Journal, Vol. 41 (1949).

2. Chow, Ven Te, "The Log-Probability Law and Its Engineering Applications." $A S C E$, Separate No. 536, Vol. 80 (November 1954). 
3. Friedman, Don G., and Janes, Byron E., Estimation of Rainfall Probabilities, Conn. Agr. Exp. Sta. (Storrs), Bull. 332, 1957.

4. Hazen, Allen, Flood Flow's. A Study of Frequency and Magnitudes. New York, John Wiley and Sons, Inc., 1930.

5. Kimball, B. F., "Assignment of Frequencies to a Completely Ordered Set of Sample Data." Trans. A.G.U., Vol. 27, No. VI (1946).

6. Linsley, Ray K. Jr., Kohler, Max A., and Paulhus, Joseph L. H., Applied Hydrology. New York, McGraw-Hill Book Company, Inc., 1949.

7. Pearson, K., Tables of the Incomplete Ganma Function. London, 1922.

\section{APPENDIX A}

\section{Determination of a Frequency Line by the Kimball Equation}

\section{The equation is:}

$$
\begin{aligned}
& \mathrm{F}=\frac{\mathrm{m}}{\mathrm{N}+1} \quad \text { or } \mathrm{T}=\frac{\mathrm{N}+1}{\mathrm{~m}} \\
& \mathrm{~F}=\text { per cent frequency or probability } \\
& \mathrm{T}=\text { return period in years, or recurrence interval } \\
& \mathrm{m}=\text { rank number in an array of decreasing order of magnitude } \\
& \mathrm{N}=\text { number of years of record }
\end{aligned}
$$

\section{Procedure}

1. Tabulate the average annual rainfall for the State.

2. Array the rainfall amounts in order of decreasing magnitude, as in Table A.

3. Compute and tabulate the plotting position, i.e., per cent frequency or return period, by the formula.

4. Plot the arrayed rainfall amounts against the per cent frequency on probability paper, see Figure 1.

5. Draw the line of best fit by eye, giving less weight to single points that plot far out of line. 
Table A

\begin{tabular}{|c|c|c|c|c|}
\hline Year & $\begin{array}{c}\text { Av. Annual } \\
\text { Precipitation } \\
\text { Inches }\end{array}$ & $\mathbf{m}$ & $\begin{array}{l}\text { Arrayed } \\
\text { Inches }\end{array}$ & $\begin{array}{c}\% \text { Frequency } \\
\text { (F) }\end{array}$ \\
\hline 1926 & 49.60 & 1 & 54.43 & 3.0 \\
\hline 1927 & 49.14 & 2 & 53.07 & 6.1 \\
\hline 1928 & 43.28 & 3 & 51.55 & 9.1 \\
\hline 1929 & 46.77 & 4 & 51.13 & 12.1 \\
\hline 1930 & 25.43 & 5 & 50.61 & 15.2 \\
\hline 1931 & 42.36 & 6 & 49.86 & 18.2 \\
\hline 1932 & 43.86 & 7 & 49.60 & 21.2 \\
\hline 1933 & 48.65 & 8 & 49.14 & 24.2 \\
\hline 1934 & 37.61 & 9 & 48.68 & 27.3 \\
\hline 1935 & 51.13 & 10 & 48.65 & 30.3 \\
\hline 1936 & 46.12 & 11 & 48.02 & 33.3 \\
\hline 1937 & 49.86 & 12 & 46.81 & 36.4 \\
\hline 1938 & 42.39 & 13 & 46.77 & 39.4 \\
\hline 1939 & 43.65 & 14 & 46.12 & .42 .4 \\
\hline 1940 & 45.12 & 15 & 45.12 & 45.4 \\
\hline 1941 & 36.59 & 16 & 45.00 & 48.5 \\
\hline 1942 & 48.68 & 17 & 44.52 & 51.5 \\
\hline 1943 & 40.72 & 18 & 43.86 & 54.5 \\
\hline 1944 & 44.52 & 19 & 43.65 & 57.5 \\
\hline 1945 & 50.61 & 20 & 43.28 & 60.6 \\
\hline 1946 & 36.69 & 21 & 42.39 & 63.6 \\
\hline 1947 & 37.22 & 22 & 42.36 & 66.7 \\
\hline 1948 & 53.07 & 23 & 41.28 & 59.7 \\
\hline 1949 & 45.00 & 24 & 41.19 & 72.7 \\
\hline 1950 & 54.43 & 25 & 40.72 & 75.8 \\
\hline 1951 & 48.02 & 26 & 39.82 & 78.8 \\
\hline 1952 & 41.28 & 27 & 37.61 & 81.8 \\
\hline 1953 & 36.53 & 28 & 37.22 & 84.8 \\
\hline 1954 & 46.81 & 29 & 36.69 & 87.9 \\
\hline 1955 & 39.82 & 30 & 36.59 & 90.9 \\
\hline 1956 & 51.55 & 31 & 36.53 & 93.9 \\
\hline 1957 & 41.19 & 32 & 25.43 & 97.0 \\
\hline
\end{tabular}




\section{APPENDIX B}

\section{Frequency of Rainfall by the Log-Probability Method}

Hazen (4) developed a method of computing frequency curves based on the assumption that the logarithms of the variable are normally distributed. The procedure used empirically determined log-probability frequency factors to handle skewness. Chow (2) later computed a table of theoretically correct log-probability frequency factors for a range of skew coefficients from 0 to 5.0 .

Plotting positions are determined by the formula:

$$
\begin{aligned}
& \mathrm{y}_{\mathrm{e}}=\overline{\mathrm{y}}\left(\mathrm{KC}_{\mathrm{r}}+1\right) \\
& \mathrm{y}_{\mathrm{c}}=\text { plotting positions, per cent frequency, on the theoretical } \\
& \text { curve } \\
& \overline{\mathrm{y}}=\text { mean value of the data } \\
& \mathrm{K}=\text { log-probability frequency factor from table calculated by } \\
& \text { Chow } \\
& \mathrm{C}_{\mathrm{v}}=\text { coefficient of variation } \\
& C_{v}=\sqrt{N \leq y^{2}-(\leq y)^{2}} \\
& \Sigma y \\
& \mathrm{~N}=\text { number of years of record } \\
& \mathrm{y}=\text { annual value of rainfall in inches }
\end{aligned}
$$

\section{Procedure}

1. Tabulate the average annual water year rainfall, see Table B.

2. Determine $\mathbf{N}$, and calculate $\Sigma \mathrm{y}, \Sigma \mathrm{y}^{2}$, and $(\Sigma \mathrm{y})^{2}$.

3. Calculate $\mathrm{C}_{\mathrm{r}}$.

4. Using $\mathrm{C}_{\mathrm{r}}$, determine $\mathrm{K}$ from tables prepared by Chow.

5. Solve the equation for $\mathrm{yc}$.

6. Plot the frequency line of ye versus per cent frequency, as in Figure 2. 
Table B. Calculations for Plotting Position $y^{\mathrm{c}}$ for use in the Theoretical Log-Probability Equation. Station-Morgantown Lock and Dam, West Virginia. Annual Rainfall for Years 1932-1957, inclusive, based on Water Year-October 1 to September 30, inclusive

\begin{tabular}{|c|c|c|c|c|c|c|}
\hline Year & Rainfall & $\begin{array}{c}\text { Recurrence } \\
\text { Interval (Yrs.) }\end{array}$ & $\mathbf{K}$ & $\mathbf{K C}_{\mathrm{r}}$ & $\mathbf{y}_{\mathrm{e}}$ & $\begin{array}{l}\text { Per Cent } \\
\text { Frequency }\end{array}$ \\
\hline 1932 & 38.92 & 1.01 & -2.04 & -0.28 & 30.61 & 99 \\
\hline 1933 & 53.34 & 2 & -0.07 & -0.01 & 42.08 & 50 \\
\hline 1934 & 35.73 & 5 & 0.81 & 0.11 & 47.19 & 20 \\
\hline 1935 & 39.77 & 20 & 1.75 & 0.24 & 52.71 & 5 \\
\hline 1936 & 40.05 & 100 & 2.62 & 0.36 & 57.81 & 1 \\
\hline 1937 & 46.99 & & & & & \\
\hline 1938 & 42.50 & & & & & \\
\hline 1939 & 47.00 & & & & & \\
\hline 1940 & 40.26 & & & & & \\
\hline 1941 & 37.72 & & & & & \\
\hline 1942 & 42.50 & & & & & \\
\hline 1943 & 43.89 & & & & & \\
\hline 1944 & 37.08 & & & & & \\
\hline 1945 & 53.15 & & & & & \\
\hline 1946 & 39.52 & & & & & \\
\hline 1947 & 35.16 & & & & & \\
\hline 1948 & 47.18 & & & & & \\
\hline 1949 & 39.12 & & & & & \\
\hline 1950 & 47.43 & & & & & \\
\hline 1951 & 46.34 & & & & & \\
\hline 1952 & 48.69 & & & & & \\
\hline 1953 & 35.08 & & & & & \\
\hline 1954 & 35.85 & & & & & \\
\hline 1955 & 42.12 & & & & & \\
\hline 1956 & 54.68 & & & & & \\
\hline 1957 & 35.13 & & & & & \\
\hline $\mathrm{N}$ & 26 & & & & & \\
\hline$\Sigma y$ & 1105.20 & & & & & \\
\hline$s y^{2}$ & $47,857.66$ & & & & & \\
\hline$(\Sigma y)^{2}$ & $1,221,467.04$ & & & & & \\
\hline y & 42.51 & & & & & \\
\hline
\end{tabular}




$$
\begin{aligned}
C_{\mathrm{v}} & =\frac{\sqrt{\mathrm{N \Sigma} \mathrm{y}^{2}-(\Sigma \mathrm{y})^{2}}}{\Sigma \mathrm{y}}=\frac{\sqrt{1,244,299.16-1,221,467.04}}{1105.20}=\frac{\sqrt{22,832.12}}{1105.20} \\
& =\frac{151.10}{1105.20}=0.137 \\
\mathrm{y}_{\mathrm{e}} & =(\mathrm{KCV}+1) \overline{\mathrm{y}} \\
\mathrm{y}_{\mathrm{c}} & =(-.28+1) 42.51 \\
\mathrm{y}_{\mathrm{c}} & =30.61
\end{aligned}
$$

\section{APPENDIX C}

\section{The Incomplete Gamma Distribution}

Barger and Thom (1) have suggested that the incomplete gamma function could be used for studying weekly, monthly, or annual rainfall distributions. On the basis that this model is appropriate, the expression for cumulative rainfall probability is, according to Friedman and Janes,

$$
G_{(x)}=\rho+(1-\rho) \int_{0}^{x}\left[\frac{x^{\gamma-1} e^{-\frac{x}{\beta}}}{\beta^{\gamma} \Gamma(\gamma)}\right] d x
$$

$G(x)$ is the probability of ozcurrence of rain amounts less than or equal to $\mathrm{x}$ inches. $p=\mathrm{P}=\frac{\mathrm{y}}{\mathrm{N}}$ where $\mathrm{y}$ is the number of times no rain occurred and $\mathrm{N}$

$$
\gamma=g=\frac{1+\sqrt{1+\frac{4}{3}\left[\ln \bar{x}-\frac{1}{n} \sum_{i}^{n} \ln x_{i}\right]}}{4\left[\ln \bar{x}-\frac{1}{n} \sum_{i}^{n} \ln x_{i}\right]}
$$

n

The average rainfall $\bar{x}$ and the sum of the natural logarithms $\Sigma \ln X i$ are

based on periods when rain actually occurred, that is $\mathrm{n}=\mathrm{N}-\mathrm{y}$.

The procedure used to obtain the desired solution of the equation is as follows: 
1. Tabulate monthly rainfall amounts as has been done in Table $\mathrm{C} 1$ for May rainfall at Wardensville, West Virginia. The data were arrayed in Column 1 for ease in handling the logarithms.

2. Record in Column 2 the natural logarithms of the rainfall amounts.

$$
1 \mathrm{n}
$$

3. Determine $N, n, y, \bar{x}, \ln \vec{x}, \frac{1}{n} \sum_{i} \ln X i$. Calculate $g, b$, and $P$ from the relationships given above.

$$
\text { 4. Calculate values in Column } 3 \text { from } u=\frac{x}{b \sqrt{g}}
$$

5. Using the calculated values of $\mathrm{u}$ and $\mathrm{p}$, read the cumulative probability from Pearson's Tables of the Incomplete Gamma Function (7) and enter in Column 4.

6. Column 4 is then plotted against the corresponding rainfall amount to obtain the curve as shown in Figure 4.

7. When periods with no rain occur, as in week 32 for Elkins, Table $\mathrm{C} 2$, Column 5 is calculated by multiplying the probability by the proportion of rain cases, i.e., (1-P) $\mathrm{F}(\mathrm{x})$. Adding to Column 5 the proportion of no rain cases, $\mathrm{P}=\frac{2}{30}=.067=.07$, gives the probability to plot against the corresponding rainfall amounts as is shown in Figure 3.

Table C1. Wardensville, West Virginia-May Rainfall Probability Incomplete Gamma Calculations

\begin{tabular}{c|c|c|c}
\hline \hline $\begin{array}{c}\mathbf{1} \\
\text { Rainfall }\end{array}$ & $\begin{array}{c}\mathbf{2} \mathbf{L} \mathbf{x} \\
\mathbf{u}=\mathbf{3} \mathbf{5 0 4} \mathbf{x}\end{array}$ & $\begin{array}{c}\mathbf{4} \\
\mathbf{F}(\mathbf{x})^{*}\end{array}$ \\
\hline .16 & -1.8326 & .08 & .00 \\
.64 & -.4463 & .32 & .02 \\
.69 & -.3711 & .35 & .03 \\
1.47 & .3853 & .74 & .15 \\
1.48 & .3920 & .75 & .16 \\
1.83 & .6043 & .92 & .24 \\
2.29 & .8286 & 1.15 & .35 \\
2.34 & .8502 & 1.18 & .36 \\
2.44 & .8920 & 1.23 & .40 \\
2.55 & .9361 & 1.28 & .42 \\
2.58 & .9478 & 1.30 & .43 \\
2.65 & .9746 & 1.34 & .44 \\
2.68 & .9858 & 1.35 & .44 \\
2.71 & .9970 & 1.37 & .47 \\
\hline
\end{tabular}


TABLE C1. CONTINUED

\begin{tabular}{|c|c|c|c|c|}
\hline & $\stackrel{1}{\text { Rainfall }}$ & $\begin{array}{c}2 \\
\operatorname{Ln} x\end{array}$ & $u=.504 x$ & $\begin{array}{c}4 \\
\mathbf{F}(\mathbf{x}) *\end{array}$ \\
\hline & 2.77 & 1.0188 & 1.40 & .48 \\
\hline & 2.99 & 1.0953 & 1.51 & .51 \\
\hline & 3.23 & 1.1725 & 1.63 & .57 \\
\hline & 3.56 & 1.2698 & 1.79 & .63 \\
\hline & 3.67 & 1.3002 & 1.85 & .64 \\
\hline & 3.67 & 1.3002 & 1.85 & .64 \\
\hline & 3.75 & 1.3218 & 1.89 & .66 \\
\hline & 3.77 & 1.3271 & 1.90 & .66 \\
\hline & 4.15 & 1.4231 & 2.09 & .72 \\
\hline & 4.61 & 1.5282 & 2.32 & .78 \\
\hline & 4.81 & 1.5707 & 2.42 & .80 \\
\hline & 5.06 & 1.6214 & 2.55 & .83 \\
\hline & 5.25 & 1.6582 & 2.65 & .85 \\
\hline & 5.34 & 1.6752 & 2.69 & .86 \\
\hline & 5.94 & 1.7817 & 2.99 & .90 \\
\hline & 6.24 & 1.8310 & 3.14 & .91 \\
\hline & 6.70 & 1.9021 & 3.38 & .94 \\
\hline Totals & 102.02 & +30.9410 & & \\
\hline
\end{tabular}

$\mathrm{N}=31$

* From Pearson's Tables $\mathrm{p}=1.75 ; \mathrm{u}=.504 \mathrm{x}$

\section{Calculations for May Rainfall Incomplete Gamma Distribution}

$$
\begin{aligned}
& \mathrm{N}=31 \quad \mathrm{y}=0 \\
& \overline{\mathrm{x}}=\frac{102.02}{31}=3.29^{\prime \prime} \quad \ln \overline{\mathrm{x}}=1.1909 \\
& \frac{1}{\mathrm{n}} \mathrm{\Sigma} \quad \ln \quad \mathrm{Xi}=\frac{30.9410}{31}=.9981 \\
& \ln \overline{\mathrm{x}}-\frac{1}{\mathrm{n}} \mathrm{\Sigma} \ln \mathrm{Xi}=1.1909-.9981=.1928 \\
& \mathrm{~g}=\frac{1+\sqrt{1+4 / 3(.1928)}}{4 \times .1928}=\frac{1+\sqrt{1.2570}}{.7712}
\end{aligned}
$$




$$
\begin{gathered}
\mathrm{g}=\frac{1+1.1212}{.7712}=\frac{2.1212}{.7712}=2.750 \\
\mathrm{~b}=\frac{\overline{\mathrm{x}}}{\mathrm{g}}=\frac{3.29}{2.750}=1.196 \\
\mathrm{u}=\frac{\mathrm{x}}{\mathrm{b} \sqrt{\mathrm{g}}}=\frac{\mathrm{x}}{1.196 \times 1.658}=\frac{\mathrm{x}}{1.983}=.504 \mathrm{x} \\
\mathrm{p}=\mathrm{g}-1=2.75-1.00=1.75
\end{gathered}
$$

\begin{tabular}{|c|c|c|c|c|c|}
\hline $\begin{array}{c}1 \\
\text { Arrayed }\end{array}$ & $\begin{array}{c}2 \\
\ln x \\
\end{array}$ & $\begin{array}{c}3 \\
\mathbf{U}\end{array}$ & $\begin{array}{c}4 \\
F(x)^{*}\end{array}$ & $\begin{array}{c}5 \\
(1-P) F(x)\end{array}$ & $\begin{array}{c}{ }^{6} \\
\text { Add No } \\
\text { Rain (.07) }\end{array}$ \\
\hline 0 & - & .00 & .00 & .00 & .07 \\
\hline 0 & - & .00 & .00 & .00 & .07 \\
\hline .01 & -4.6052 & .02 & .02 & .02 & .09 \\
\hline .02 & -3.9120 & .04 & .03 & .03 & .10 \\
\hline .04 & -3.2189 & .08 & .06 & .06 & .13 \\
\hline .05 & -2.9957 & .09 & .07 & .06 & .13 \\
\hline .06 & -2.8134 & .11 & .09 & .08 & .15 \\
\hline .14 & -1.9661 & .26 & .19 & .18 & .25 \\
\hline .16 & -1.8326 & .30 & .23 & .21 & .28 \\
\hline .19 & -1.6607 & .36 & .27 & .25 & .32 \\
\hline .27 & -1.3093 & .51 & .36 & .33 & .40 \\
\hline .28 & -1.2730 & .53 & .38 & .35 & .42 \\
\hline .34 & -1.0788 & .64 & .45 & .42 & .49 \\
\hline .37 & -.9942 & .70 & .47 & .44 & .51 \\
\hline .42 & -.8675 & .79 & .52 & .48 & .55 \\
\hline .47 & -.7550 & .89 & .57 & .53 & .60 \\
\hline .51 & -.6733 & .96 & .60 & .56 & .63 \\
\hline .54 & -.6162 & 1.02 & .62 & .58 & .65 \\
\hline .57 & -.5621 & 1.08 & .64 & .60 & .67 \\
\hline .66 & -.4155 & 1.25 & .69 & .64 & .71 \\
\hline .66 & -.4155 & 1.25 & .69 & .64 & .71 \\
\hline .67 & -.4005 & 1.27 & .70 & .65 & .72 \\
\hline .86 & -.1508 & 1.62 & .79 & .73 & .80 \\
\hline .95 & -.0513 & 1.80 & .82 & .76 & .83 \\
\hline .97 & -.0305 & 1.83 & .82 & .76 & .83 \\
\hline .99 & -.0100 & 1.87 & .84 & .78 & .85 \\
\hline
\end{tabular}

Table C2. Elkins Week 32 (Least Av. Precip.) Incomplete Gamma Calculations 
TABLE C2. CONTINUED

\begin{tabular}{c|c|c|c|c|c}
\hline $\mathbf{1}$ & $\mathbf{2}$ & $\mathbf{3}$ & $\mathbf{4}$ & $\mathbf{5}$ & $\begin{array}{c}\mathbf{6} \\
\text { Add No } \\
\text { Rain (.07) }\end{array}$ \\
\hline 1.08 & +.0770 & 2.04 & .86 & .80 & .87 \\
1.11 & +.1044 & 2.10 & .87 & .81 & .88 \\
1.22 & +.1988 & 2.30 & .89 & .83 & .90 \\
1.77 & +.5710 & 3.34 & .96 & .89 & .96 \\
\hline 15.38 & -31.6569 & & & & \\
\hline
\end{tabular}

* $\mathrm{F}(\mathrm{s})$ from Pearson's Tables $\mathrm{p}=.08 ; \mathrm{u}=1.89 \mathrm{x} ; 1-\mathrm{P}=1-.067=.93$

$$
\begin{aligned}
& \mathrm{y}=2 \quad \mathrm{P}=\frac{2}{30}=.067 \\
& \overrightarrow{\mathrm{x}}=\frac{15.38}{28}=.55^{\prime \prime} \quad \ln \mathrm{x}=-.5974 \\
& \frac{1}{\mathrm{n}} \mathrm{\Sigma} \ln \mathrm{Xi}=\frac{-31.6569}{28}=-1.1306 \\
& \ln \mathrm{x}-\frac{1}{\mathrm{n}} \mathrm{x} \ln \mathrm{Xi}=-.5974-(-1.1306) \\
& =.5332 \\
& \mathrm{~g}=\frac{1+\sqrt{1+1.33(.5332)}}{\mathrm{g}}=\frac{1+1.31}{2.1328}=\frac{2.31}{2.1328} \\
& \mathrm{~b}=\frac{\overline{\mathrm{x}}}{\mathrm{g}}=\frac{.55}{1.08}=.51 \\
& \mathrm{p}=\mathrm{g}-1=1.08-1=\frac{\mathrm{x}}{\mathrm{x}}=\frac{\mathrm{x}}{.51(1.04)} \\
& \mathrm{u}=\frac{.53}{\mathrm{~b} \sqrt{\mathrm{g}}}=\frac{.51}{\mathrm{u}}=\frac{1.89 \mathrm{x}}{1.08} \\
& \mathrm{l}-\mathrm{P}=1.00-.067=.93
\end{aligned}
$$


Table C3. Elkins Week 19 (Greatest Av. Precip.) Incomplete Gamma Calculations

\begin{tabular}{|c|c|c|c|}
\hline Arrayed & $\ln x$ & $\mathbf{u}$ & $\mathbf{F}(\mathbf{x})^{*}$ \\
\hline .04 & -3.2189 & .03 & .00 \\
\hline .11 & -2.2073 & .09 & .02 \\
\hline .28 & -1.2730 & .23 & .08 \\
\hline .45 & -0.7985 & .37 & .16 \\
\hline .45 & -0.7985 & .37 & .16 \\
\hline .55 & -0.5978 & .45 & .20 \\
\hline .67 & -0.4005 & .55 & .26 \\
\hline .92 & -0.0834 & .75 & .37 \\
\hline .98 & -0.0202 & .80 & .40 \\
\hline .99 & -0.0100 & .81 & .40 \\
\hline 1.01 & +0.0100 & .83 & .41 \\
\hline 1.04 & +0.0392 & .85 & .42 \\
\hline 1.10 & +0.0953 & .90 & .45 \\
\hline 1.11 & +0.1044 & .91 & .45 \\
\hline 1.22 & +0.1988 & 1.00 & .49 \\
\hline 1.28 & +0.2469 & 1.05 & .51 \\
\hline 1.53 & +0.4253 & 1.25 & .59 \\
\hline 1.54 & +0.4318 & 1.26 & .59 \\
\hline 1.57 & +0.4511 & 1.29 & .61 \\
\hline 1.79 & +0.5822 & 1.47 & .67 \\
\hline 1.81 & +0.5933 & 1.48 & .68 \\
\hline 1.82 & +0.5988 & 1.49 & .69 \\
\hline 1.84 & +0.6098 & 1.51 & .69 \\
\hline 2.01 & +0.6981 & 1.65 & .73 \\
\hline 2.13 & +0.7561 & 1.75 & .75 \\
\hline 2.53 & +0.9282 & 2.07 & .82 \\
\hline 2.63 & +0.9670 & 2.16 & .84 \\
\hline 3.46 & +1.2413 & 2.84 & .92 \\
\hline 3.51 & +1.2556 & 2.88 & .93 \\
\hline 5.72 & +1.7440 & 4.69 & .99 \\
\hline 46.09 & +2.5691 & & \\
\hline
\end{tabular}

$* \mathrm{~F}(\mathrm{x})$ from Pearson's Tables $\mathrm{p}=.59 ; \mathrm{u}=.82 \mathrm{x}$ 


$$
\begin{aligned}
& \overline{\mathrm{x}}=\frac{46.09}{30}=1.54^{\prime \prime} \quad \ln \overline{\mathrm{x}}=.4318 \\
& \frac{\mathrm{l}}{\mathrm{n}} \mathrm{\Sigma} \ln \mathrm{Xi}=\frac{2.5691}{30}=.0856 \\
& \ln \overline{\mathrm{x}}-\frac{1}{\mathrm{n}} \mathrm{\Sigma} \ln \mathrm{Xi}=.4318-.0856=.3462 \\
& \mathrm{~g}=\frac{1+\sqrt{1-1.33(.3462)}}{4 \times .3463}=\frac{1+\sqrt{1.4606}}{1.3852} \\
& \mathrm{~g}=\frac{1+1.2086}{1.3852}=\frac{2.2086}{1.3852} \\
& \mathrm{~g}=1.59 \\
& \mathrm{p}=\mathrm{g}-1=1.59-1=.59 \\
& \mathrm{~b}=\frac{\overline{\mathrm{x}}}{\mathrm{g}}=\frac{1.54}{1.59}=.97 \\
& \mathrm{u}=\frac{\mathrm{x}}{\mathrm{b} \sqrt{\mathrm{g}}}=\frac{\mathrm{x}}{.97 \sqrt{1.59}}=\frac{\mathrm{x}}{.97 \times 1.26}=\frac{\mathrm{x}}{1.22} \\
& \mathrm{u}=\frac{.82 \mathrm{x}}{\mathrm{x}}
\end{aligned}
$$





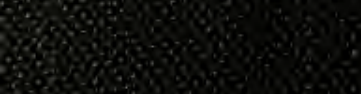

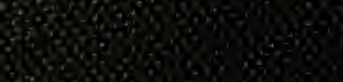

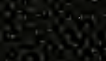

30908

698

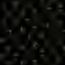

